\title{
Chromium in Corundum: Ultra-high Contents Under Reducing Conditions
}

Sarah E.M. Gain ${ }^{1,2 *}$, William L. Griffin ${ }^{2}$, Martin Saunders ${ }^{1}$ and Vered Toledo ${ }^{3}$

1. Centre for Microscopy, Characterisation and Analysis, The University of Western Australia, Australia.

2. ARC Centre of Excellence for Core to Crust Fluid Systems (CCFS) and Centre for Geochemical Evolution and Metallogeny of Continents (GEMOC), Earth and Planetary Sciences, Macquarie University, Australia.

3. Shefa Yamim (A.T.M.) Ltd., Netanya, Israel.

* Corresponding author: sarah.gain@uwa.edu.au

An exploration project run by Shefa Yamim (A. T. M.) Ltd has recovered a variety of gemstone minerals from Cretaceous pyroclastic vents and associated alluvial deposits at Mt Carmel, Israel [1]. Among these are several types of corundum $\left(\mathrm{Al}_{2} \mathrm{O}_{3}\right)$, including rubies with $<2 \mathrm{wt} \% \mathrm{Cr}_{2} \mathrm{O}_{3}$ and sapphires in a variety of colours from yellows through to greens, blues and purples, with a range of chemical impurities e.g. Ti, Fe, V, Ga. The most scientifically interesting type of corundum is the inclusion-rich 'Carmel Sapphire ${ }^{\mathrm{TM}}$ ', which contains a variety of mineral phases; some of these have only been seen in meteorites previously, e.g. tistarite $\left(\mathrm{Ti}_{2} \mathrm{O}_{3}\right)$ [2], and others have not previously been described, e.g. carmeltazite $\left(\mathrm{ZrAl}_{2} \mathrm{Ti}_{4} \mathrm{O}_{11}\right)$ [3]. These minerals indicate very low oxygen fugacities, at least 7 log units below the Iron-Wustite buffer ( $\Delta \mathrm{IW}-7)$, and are interpreted as reflecting the presence of $\mathrm{CH}_{4}+\mathrm{H}_{2}$-rich fluids [1,4]. These discoveries have led to a new understanding of fluid transfer and redox conditions in the crust and mantle.

Here we describe another variety of Cr-rich corundum (Fig. 1) with Cr concentrations up to 32 wt.\% $\mathrm{Cr}_{2} \mathrm{O}_{3}$, representing a composition in the solid solution series between corundum and eskolaite $\left(\mathrm{Cr}_{2} \mathrm{O}_{3}\right)$, and considerably more Cr-rich than previously known examples. These crystals are a deep purple (Fig. 1), but while purple in corundum usually is due to a combination of $\mathrm{Ti}$ and $\mathrm{Cr}$, in this case the crystals are Ti-free and contain much higher concentrations of $\mathrm{Cr}$. The cores of the crystals have relatively low $\mathrm{Cr}$ concentrations (1-2 wt.\% $\left.\mathrm{Cr}_{2} \mathrm{O}_{3}\right)$ and the $\mathrm{Cr}$ concentration increases towards the rim. In the highest-Cr areas, the material consists of subgrains with small but distinct variations in $\mathrm{Cr}$ content (Fig. 1a, 2). On the surface of the illustrated crystal there are abundant balls $(<10 \mu \mathrm{m}$ to 100 's of $\mu \mathrm{m})$ of native $\mathrm{Cr}$; Transmission Electron Microscopy (TEM) studies show that these are associated with chromium nitride CrN (carlsbergite; Fig. 2), otherwise known only from iron meteorites.

Electron Energy Loss Spectroscopy (EELS) analyses show that the valence of the Cr changes from $\mathrm{Cr}^{3+}$ in the corundum (both low-Cr and high-Cr types) to $\mathrm{Cr}^{2+}$ in the carlsbergite and finally $\mathrm{Cr}^{0}$ in the chromium metal. The coexistence of all three valence states suggests that the oxygen fugacity was constrained by the $\mathrm{CrO} / \mathrm{Cr}$ buffer, and that $\mathrm{Cr}$ was undergoing a crystallographically-controlled disproportionation, $\mathrm{Cr}^{2+} \rightarrow \mathrm{Cr}^{3+}+\mathrm{Cr}^{0}$. The oxygen fugacity implied by this reaction lies at ca $\Delta \mathrm{IW}-5$, less reducing than the conditions inferred from the $\mathrm{Ti}^{3+}$ bearing, but $\mathrm{Cr}$-free, assemblages in the Carmel Sapphire. These unusual high-Cr rubies thus appear to represent an earlier stage in the crystallization of the Mt Carmel magmas. 


\section{References:}

[1] WL Griffin et al., Mineralogy and Petrology 112 (2018), p. 101.

[2] WL Griffin et al., Geology 44 (2016), p. 815.

[3] WL Griffin et al., Minerals 8 (2018), p. 601.

[4] SEM Gain et al., elsewhere in these proceedings.
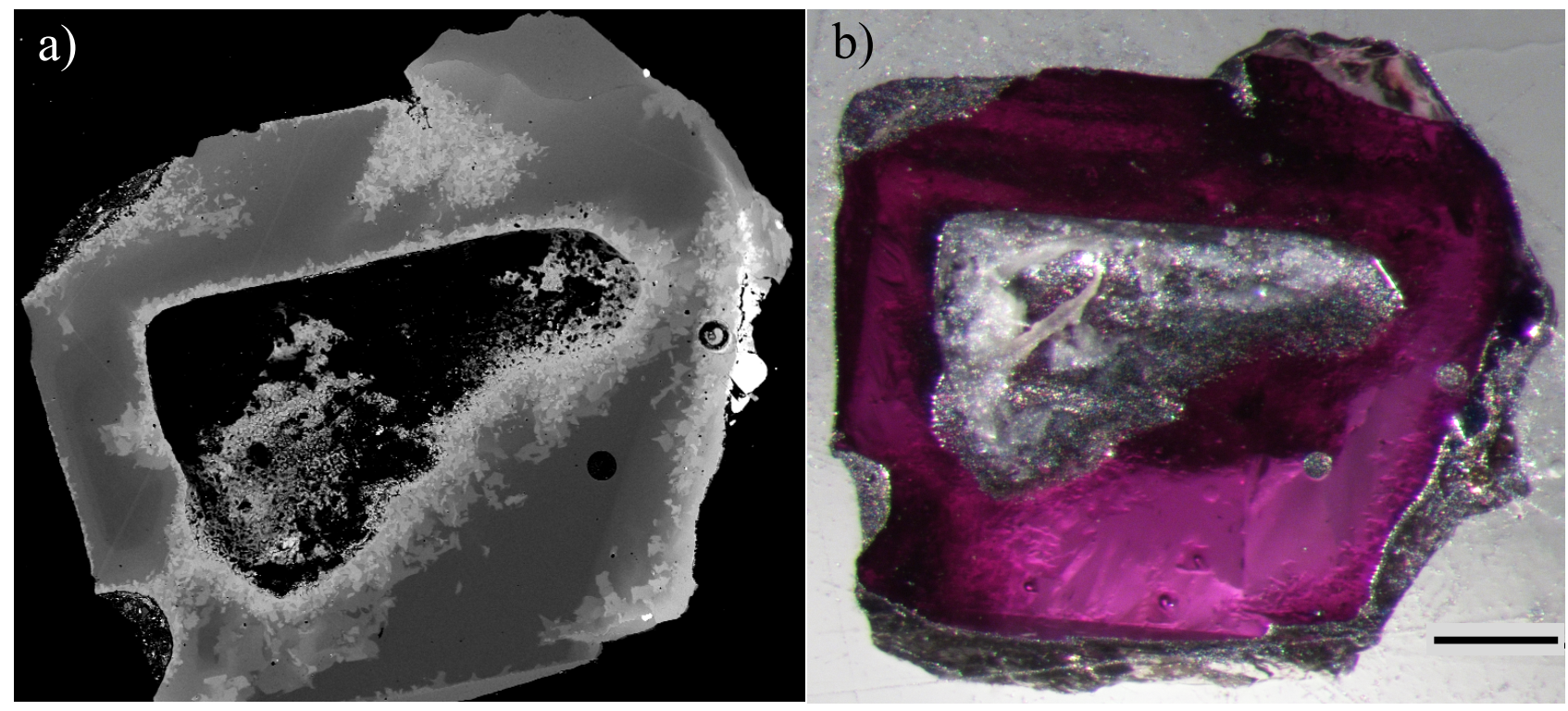

Figure 1. Chromium rich corundum; a) backscattered electron - scanning electron microscope (BSE-SEM) image, b) light microscope image; scale bar $200 \mu \mathrm{m}$.

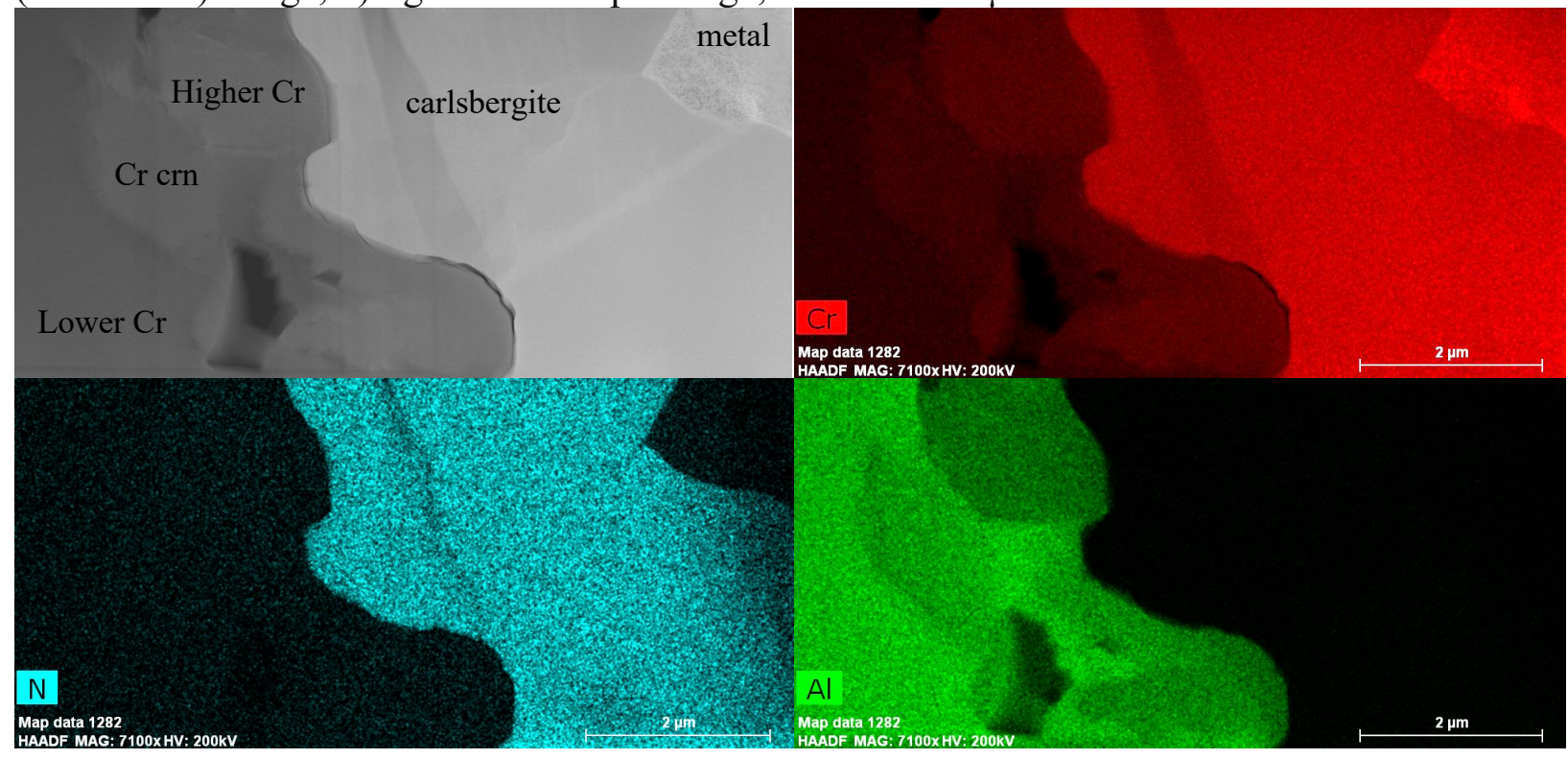

Figure 2. High angle annular dark field (HAADF) Scanning TEM (STEM) image and associated EDS element maps of a Focused Ion Beam (FIB-SEM) prepared TEM sample, showing the carlsbergite in the boundary between the chromium-rich corundum (crn) and the chromium metal, and varying $\mathrm{Cr}$ concentrations in the corundum. 